\title{
Princípio Da Vedação De Retrocesso Ambiental: Uma Visão Crítica
}

\author{
Paulo De Bessa Antunes * \\ Universiadade Federal do Rio de Janeiro, Programa de Pós-Graduação em Direito, Rio de Janeiro-RJ, \\ Brasil. \\ https://orcid.org/0000-0003-0375-0213
}

Resumo: O artigo tem por objetivo discutir o chamado Princípio da Vedação do Retrocesso Ambiental. Como o artigo demonstra, o princípio é uma adaptação mecânica do historicismo ao direito ambiental e de fato, não encontra respaldo na Constituição, nem nas principais decisões do Supremo Tribunal Federal. Trata-se de uma construção que, todavia, tem se espalhado entre os autores e algumas decisões do Superior Tribunal de Justiça. O artigo demonstra que a maior ou menor proteção ambiental, inclusive com modificações legislativas depende, essencialmente, da conjuntura econômica.

Palavras-chave: Retrocesso. Historicismo. Direito ambiental. Proteção ambiental.

\footnotetext{
* Doutor em Direito. Líder de Pesquisa Acadêmica cadastrada no CNPq. Visiting Scholar de Lewis and Clark College, Portland, Oregon. Professor adjunto de Direito Ambiental da Universidade Federal do Estado do Rio de Janeiro (UNIRIO). Professor Associado da Universidade Federal do Estado do Rio de Janeiro (UNIRIO); Coordenador do Programa de Pós Graduação em Direito. E-mail: paulo.antunes@unirio.br
}

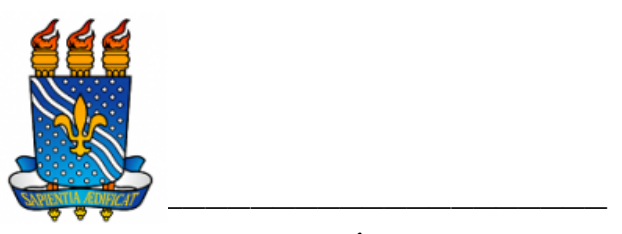

UNIVERSIDADE FEDERAL DA PARAÍBA

Programa de Pós-Graduação em Ciências Jurídicas DOI: https://doi.org/10.22478/ufpb.1678-2593.2021v20n44.51872 


\title{
Princípio Da Vedação De Retrocesso Ambiental: Uma Visão Crítica
}

\section{Paulo De Bessa Antunes ${ }^{1}$}

\begin{abstract}
Enquanto isso, embora Rafael seja um homem de grande erudição e grande conhecedor das coisas deste mundo, não posso concordar com tudo o que ele disse. Contudo, devo confessar que há muita coisa na República de Utopia que eu desejaria ver imitada em nossas cidades - coisa que mais desejo do que espero

(MORE, 2004).
\end{abstract}

Com efeito, quanto mais incoerência e contradições houver no conteúdo das regras de um direito, menos possíveis serão as definições que devem conter as regras gerais, e estas tornam imediatamente visível, em toda a sua crueza, a contradição que é, aqui, a injustiça

(HEGEL, 1997).

\section{INTRODUÇÃO}

Este artigo busca examinar o chamado princípio da vedação de retrocesso ambiental de forma crítica, em especial quanto à sua aplicação aos Espaços Territoriais Especialmente Protegidos [ETEP] e, sobretudo, às Unidades de Conservação [UC's]. O tema nos últimos anos tem se expandido no Direito Ambiental Brasileiro, sendo importante no atual debate sobre a proteção ambiental no Brasil.

Como se sabe, o chamado princípio da vedação de retrocesso - é importante consignar que não há um consenso sobre o nome do princípio, conforme apontado por Mello (2014, p.61) que pode ser

\footnotetext{
${ }^{1}$ Procurador regional da República (aposentado). Foi Presidente da Comissão Permanente de Direito Ambiental do Instituto dos Advogados Brasileiros. Ex-chefe da Assessoria Jurídica da Secretaria de Estado do Meio Ambiente do Estado do Rio de Janeiro. Autor de diversos livros e artigos sobre Direito Ambiental.
} 
encontrado na literatura como vedação da retrogradação, vedação do retrocesso, não retorno da concretização, não retrocesso, não contrarrevolução, eficácia vedativa de retrocesso, eficácia impeditiva do retrocesso, proibição de contrarrevolução, proibição de revolução reacionária, não evolução reacionária - é um dos mais recentes a ganhar proeminência em um campo no qual os "princípios" proliferam em escala geométrica, não se sabendo ao certo as suas origens, objetivos e funções. Esta realidade faz com que o exame dos princípios seja cada vez mais necessário no campo do Direito Ambiental, devendo-se levar em consideração o disposto no artigo 20 da Lei de Introdução às Normas do Direito Brasileiro (LINDB), segundo o qual nas esferas administrativa, controladora e judicial, não se decidirá com base em valores jurídicos abstratos sem que sejam consideradas as consequências práticas da decisão.

Conforme o disposto pelo Decreto $\mathrm{n}^{0}$ 9.830, de 10 de junho de 2019, em seu artigo $3^{\circ}, \S 1^{\circ}$, valores jurídicos abstratos são "aqueles previstos em normas jurídicas com alto grau de indeterminação e abstração". Isto é, não há vedação a que decisões administrativas ou judiciais sejam tomadas com base em tais valores jurídicos abstratos, todavia, quando a situação ocorrer, faz-se necessário que o tomador da decisão indique as suas consequências práticas que "[...]no exercício diligente de sua atuação, consiga vislumbrar diante dos fatos e fundamentos de mérito e jurídicos[...]”, assim como na motivação deverá demonstrar "[...]a necessidade e a adequação da medida imposta, inclusive consideradas as possíveis alternativas e observados os critérios de adequação, proporcionalidade e de razoabilidade[...]". (BRASIL, 2019)

A Constituição Federal de 1988, no inciso III do $§ 1^{\circ}$ do artigo 225 trata especificamente da obrigação do Poder Público em relação à (1) identificação e (2) delimitação de espaços territoriais a serem especialmente protegidos [ETEP] em razão dos valores ecológicos e ambientais que ostentem, prevendo inclusive os mecanismos a serem adotados em caso de alteração ou supressão de tais espaços. 
Como já foi assinalado, o princípio da vedação de retrocesso ambiental é tema que tem crescido em importância, chegando a merecer a publicação de uma obra coletiva sob os auspícios da Comissão de Meio Ambiente, Defesa do Consumidor e Fiscalização e Controle do Senado Federal (BRASIL, 2012) que tem sido muito influente na sua divulgação. A $2^{\text {a }}$ Turma do Superior Tribunal de Justiça [ $\left.2^{\mathrm{a}} \mathrm{T}-\mathrm{STJ}\right]$ vem debatendo a matéria e construindo uma visão particular do chamado princípio da vedação de retrocesso ambiental. Por sua vez, o Supremo Tribunal Federal [STF] também tem se debruçado sobre a matéria e afirmado posicionamento bastante divergente da peculiar interpretação dada pela $2^{\mathrm{a}} \mathrm{T}$ - STJ.

Conforme será examinado ao longo do artigo, a ideia de vedação de retrocesso é fruto de uma concepção historicista que supõe um futuro inevitável no qual a Humanidade alcançará uma "era de ouro". De acordo com tal compreensão, não há retorno e o Direito Ambiental deve ser uma sentinela para impedir o retorno a condições "menos protetoras" do ambiente. Contraditoriamente, cuida-se de uma concepção estática e anti-humanista do meio ambiente, pois as modificações ambientais, ainda que em favor do Ser Humano devem ser rejeitadas, por incompatíveis com o "desenvolvimento sustentável”, conceito que, no contexto, o conteúdo é variável e adaptável ao que se pretenda proibir.

Este artigo é, fundamentalmente, construído a partir de pesquisa doutrinária e jurisprudencial, buscando identificar o conteúdo concreto do princípio da vedação do retrocesso ambiental. Mesmo reconhecendo a impossibilidade da aplicação concreta do Direito sem um tanto de criação por parte do intérprete, esta deve ser reduzida a um mínimo compatível com a certeza e a segurança jurídica. 


\section{PRINCÍPIO DA VEDAÇÃO DE RETROCESSO}

\subsection{Origens do Princípio da Vedação de Retrocesso}

O chamado princípio da vedação de retrocesso tem origem tipicamente europeia, encontrando sua origem imediata no Direito Alemão, a partir de em bates jurídicos e questionamentos judiciais relativos à crise do Estado de Bem Estar Social em função de dificuldades econômicas gerais e suas repercussões sobre os regimes de previdência social. A discussão girava em torno do direito subjetivo público (uma propriedade) que seria garantido constitucionalmente e o Estado, portanto, estava obrigado a assegurá-lo. A Corte Constitucional chegou ao entendimento, em síntese, de os direitos sociais estão condicionados pelos (1) recursos econômicos existentes e (2) por aquilo que o indivíduo pode exigir razoavelmente da sociedade (MELLO, 2014, p. 68).

A existência de um princípio jurídico que proíba o "retrocesso" a regimes jurídicos "menos protetores", seja do ponto de vista social, seja do ponto de vista ambiental é, parafraseando Kelsen (1995), uma “ilusão". Um excelente exemplo é o representado pela crise de 2008 que abalou a Europa e o mundo, sendo a pior crise desde 1930 (KERSHAW, 2018), gerando enorme desemprego e decréscimo da atividade econômica. Pois, bem, buscou-se impedir os reflexos negativos sobre os trabalhadores, sustentando que o princípio da vedação de retrocesso impediria a redução de pensões ou mesmo salários. Uma das mais interessantes discussões sobre a matéria e a que mostra de forma mais avassaladora a força dos fatos é a relativa ao artigo $81^{\circ}$ (a) da Constituição Portuguesa que estabelece incumbir prioritariamente ao Estado, no âmbito econômico e social “[...] [p]romover o aumento do bem-estar social e econômico e da qualidade de vida das pessoas, em especial das mais desfavorecidas, no quadro de uma estratégia de desenvolvimento sustentável [...]” (PORTUGAL, 1976). 
A jurisprudência sobre o artigo é interessante. O Acórdão 39/84 do Tribunal Constitucional de Portugal, claramente afirmou a existência de uma vedação ao retrocesso o tratar de questões relativas ao Sistema Nacional de Saúde Português. Entretanto, a "força normativa" dos fatos mudou radicalmente a orientação da elevada Corte, criando-se a chamada "jurisprudência da crise". (PORTUGAL, 1984) Gomes Canotilho (2008), chegou a afirmar, sobre a vedação de retrocesso, que o discurso "que nós próprios enfatizamos noutros trabalhos" deveria ser relativizado, tendo em vista a "dramática aceitação de "menos trabalho e menos salário, mas trabalho e salário e para todos", diante do enorme desafio representado pela quebra da previdência social, pelo desemprego persistente. A nova jurisprudência está bem caracterizada pelo Acórdão no 396/2011. Em síntese: o princípio da vedação ao retrocesso cede passo à realidade.

\subsection{Vedação de Retrocesso Ambiental e o Desgaste do Princípio da Precaução}

A proibição de retrocesso, assim como o princípio da precaução [PP] e tantos outros que proliferam no Direito Ambiental, parte de um receio generalizado sobre o futuro do mundo. O medo justificável ou não - tem se tornado um dos componentes mais influentes da vida social moderna, com visíveis efeitos jurígenos (SUNSTEIN, 2005). A amplificação midiática de tragédias, de crimes e dificuldades sociais e econômicas fazem com que o cidadão médio se imagine em um mundo pior do que o dos "tempos dourados do passado", um "mundo intolerável" (DUMONT, 1988). A partir disso, cria-se um caldo de cultura essencialmente negativo, em constante atrito com inovações tecnológicas e científicas e que, no caso especificamente brasileiro, tem gerado verdadeiras perplexidades.

O princípio da vedação do retrocesso ambiental é, de certa forma, uma alternativa ao esvaziamento do PP como instrumento de paralisia das atividades econômicas utilizadoras do meio ambiente. 
Antunes (2016) demonstrou que o STF vem estabelecendo limites concretos à aplicação do princípio da precaução, buscando dar-lhe racionalidade e evitando as interpretações maximalistas. O princípio da vedação de retrocesso ambiental, por isso, surge como uma nova expressão das utopias jus ambientalistas que buscam nas normas jurídicas o que elas não podem dar. O PP é hoje um princípio desgastado, vítima da fadiga de uso, causada pelo elevado nível de banalização alcançado, sendo utilizado, com frequência, no caso das necessárias obras de infraestrutura - tecnologias conhecidas e, portanto, sem "incertezas científicas" que têm sido barradas judicialmente com base em sua errônea aplicação. Meras questões relativas a descumprimento de normas - ausência de estudos ambientais - são resolvidas com base no PP. (BRASIL, 2007)

\subsubsection{ATIVISMO ACADÊMICO}

A discussão, cada vez mais intensa, sobre o princípio da proibição de retrocesso em matéria de proteção ao meio ambiente é uma demonstração cabal da incompreensão do "lugar do direito na proteção do ambiente" (GARCIA, 2015). A partir de tal dificuldade de localização precisa do papel do Direito Ambiental na defesa ambiental, passa-se a identificar "ameaças" que "[...] podem ensejar o recuo do Direito Ambiental[...]” (BRASIL, 2012, p. 12). Elas, em resumo, seriam as seguintes (1) desregulamentação, (2) crise econômica e (3) psicológicas. A ideia de que o Direito Ambiental está ameaçado, ou seja, de que as suas normas estão se tornando menos protetoras do meio ambiente, tem por origem uma visão que tende a considerar que a humanidade e o mundo "avançam" continuamente em direção a um fim predeterminado.

Esta é uma concepção tributária da ideia de progresso constante e do padrão de desenvolvimento que vem sendo submetido a severas críticas das mais diferentes origens (CORNWALL e EADE, 
2010). Como sabemos, o Direito Ambiental tem como uma de suas mais importantes funções a organização da atividade econômica em relação à apropriação dos recursos naturais, logo ele pressupõe a utilização econômica do ambiente, sem a qual não há que se falar em proteção jurídica do ambiente. A norma jurídica ambiental busca estabelecer um equilíbrio entre as diferentes necessidades humanas, nelas incluída a boa qualidade do ambiente. Entretanto, como é autoevidente, o meio ambiente se modifica, pois a atividade humana é, em sua essência, transformadora do ambiente. $\mathrm{O}$ desenvolvimento sustentável é a fórmula ampla que, aparentemente, abriga entendimentos e visões sobre o meio ambiente muito diferentes. $\mathrm{O}$ conceito, todavia, foi tão utilizado, tão banalizado que o seu sentido está se perdendo. Praticamente não há mais nada que não seja sustentável (SCOONES, 2010).

Após o fim da Segunda Guerra Mundial, com a fundação da Organização das Nações Unidas (ONU) aos 24 de outubro de 1945, inaugurou-se uma era na qual se imaginava que as guerras iriam ser abolidas e os horrores não se repetiriam. A Carta da ONU, expressamente, assume a visão de progresso constante, sendo um dos seus objetivos "promover o progresso social". A Declaração de Estocolmo sobre o Meio Ambiente Humano em sua consideração (2) expressa claramente a noção de progresso ao invocar que a "proteção e a melhoria do meio ambiente humano" são desejos permanentes dos povos e dever de todos os Governos, por constituírem o aspecto mais relevante que afeta o bem-estar dos povos e o desenvolvimento do mundo inteiro. A Declaração do Rio sobre Meio Ambiente e Desenvolvimento, em vários de seus princípios faz menções expressas ao desenvolvimento, desde então, sustentável. Assim, a marcha para frente, em termos jurídicos, não pode ser detida e para impedir o "regresso" há que se construir um mecanismo jurídico que sirva como point of no return.

A doutrina jurídica, em especial a francesa, tem admitido que o princípio da proibição do retrocesso ambiental não é ainda um princípio reconhecido como tal, limitando-se a aparecer 
implicitamente “[...] em todas as ordens jurídicas[...]" (PRIEUR, 2011, p. 89). O mesmo Prieur admite a necessidade de promover a não regressão como um novo princípio fundamental do Direito Ambiental, logo, e, sem grande esforço intelectual, percebe-se que o princípio em questão é um não-princípio, um objetivo futuro a ser alcançado que, no fundo, se confunde com a manifestação de vontade de seus sequazes. O princípio da vedação de retrocesso não é dotado de qualquer imperatividade, diferentemente do que ocorre com os princípios jurídicos legitimamente reconhecidos e consolidados que são de aplicação obrigatória (artigo $4^{\circ}$ da LINDB). Veja-se que Michel Prieur, cita como exemplo da normatividade do princípio da vedação de retrocesso a Constituição do Butão que, segundo o consagrado autor, estabelece que $60 \%$ das florestas do país são protegidas "pela eternidade". Em sentido contrário, podemos entender que a Constituição do Butão autoriza o corte de $40 \%$ de suas florestas. (BUTÃO, 2008) No particular, deve ser relembrado que a principal atividade econômica no Butão é a exportação de energia hidrelétrica que, necessariamente, alaga áreas florestadas o que, em princípio, parece ser incompatível com a proteção "eterna” das florestas. Há que se considerar, também, que no Butão é país montanhoso e, portanto, impróprio para o uso alternativo do solo.

Na doutrina jurídica brasileira, o princípio da vedação do retrocesso, igualmente, é impreciso. Luís Paulo Sirvinskas (2014, p. 147) limita-se a afirmar que ele se constitui em um "[...]importante instrumento para o jus ambientalista [...]”, pois impede que novas leis ou atos venham a desconstituir "conquistas ambientais", acrescentando que o princípio não admite excludentes. Assim, o mencionado princípio pressupõe que as regras de Direito Ambiental estabelecem padrões de proteção ao meio ambiente que não podem ser reduzidos por normas posteriores, gerando, portanto, um padrão imutável de proteção ou, em outras palavras, a revogação de uma norma de Direito Ambiental somente pode ser considerada como juridicamente válida se aumentar a proteção - maior restrição de 
utilização econômica - ambiental. Benjamim (2012, p. 63) sustenta ser seguro afirmar que a proibição de retrocesso,

[...] apesar de não se encontrar, com nome e sobrenome, consagrada na nossa Constituição, nem em normas infraconstitucionais, e não obstante sua relativa imprecisão - compreensível em institutos de formulação recente e ainda em pleno processo de consolidação-, transformou-se em princípio geral do Direito Ambiental, a ser invocado na avaliação da legitimidade de iniciativas legislativas destinadas a reduzir o patamar de tutela legal do meio ambiente, mormente naquilo que afete em particular a) processos ecológicos essenciais, b) ecossistemas frágeis ou à beira de colapso, e c) espécies ameaçadas de extinção.

A questão que se coloca é saber como um princípio que não se encontra, “[...]com nome e sobrenome[...]" consagrado em nossa Constituição, "nem em normas infraconstitucionais", sendo dotado de "relativa imprecisão" pode ser um princípio geral de Direito Ambiental?

\subsubsection{TRANSPLANTE ACRÍTICO DE OUTRA REALIDADE JURÍDICA}

A tentativa de transplante do princípio da vedação de retrocesso para o Direito Brasileiro é equivocada, haja vista que o nosso regime jurídico constitucional, expressamente, consagra os direitos adquiridos e o ato jurídico perfeito (artigo $5^{\circ}$, XXXVI) como direitos fundamentais. Isto consagra a impossibilidade de normas com efeito retroativo, mesmo que sejam normas de ordem pública. No particular, convém relembrar o voto do Ministro Moreira Alves (BRASIL, 2007) que, ao analisar a questão dos direitos adquiridos no Brasil, afirmou que, salvo a Constituição de 1937, as Constituições brasileiras posteriores a 1934, sempre consagraram a teoria subjetiva dos direitos adquiridos, decorrendo daí que, diferentemente do que ocorre na França (FRANÇA, 1958) as leis de ordem pública não retroagem em desfavor dos direitos adquiridos por particulares, pois 
devem ser aplicadas prospectivamente, com o pagamento de indenização caso impliquem em restrição de uso e esvaziamento do conteúdo econômico da propriedade. Pensar diversamente é, com tintas verdes, postulação de ordem jurídica autoritária.

Justifica-se a teoria do efeito cliquet, no ordenamento jurídico francês, ante a inexistência de direitos adquiridos com status constitucional. Logo, não oponíveis às normas de ordem pública que, eventualmente, pudessem incidir sobre determinadas situações jurídicas já consolidadas. Tem-se, portanto, que diante da cláusula expressa em nossa Constituição relativa ao respeito aos direitos adquiridos e ao ato jurídico perfeito, é dispensável a criação de um "novo princípio" relativo à vedação de retrocesso ambiental, por redundante quando se tratar de norma de direito púbico que se pretenda aplicável a direitos adquiridos já constituídos. Não se justifica, igualmente, que se cogite em direitos adquiridos do ambiente ou da sociedade, haja vista que os direitos adquiridos se constituem em barreira jurídica ao avanço do Estado ou da "sociedade" sobre os particulares.

\subsection{A Imposição Da Realidade}

A realidade e os fatos têm força normativa e o Direito deve render-lhes homenagens. Sustenta-se que a Carta dos Direitos Fundamentais da União Europeia, ao dispor em seu artigo 37 sobre a proteção do ambiente e, nele, afirmar que as políticas da União devem se pautar por "[...] um elevado nível de proteção do ambiente e a melhoria de sua qualidade[...]" estaria implicitamente acolhendo o princípio da proibição de retrocesso, sobretudo ao proclamar que a proteção do ambiente deve ser assegurada "[...] de acordo com o princípio do desenvolvimento sustentável[...]." (SARLET; FENSTERSEIFER, 2014, p. 195-196). Primo, tem-se que nível elevado de proteção é uma fórmula aberta que, evidentemente, deve ser 
preenchida em base casuística. Secundo, um nível elevado de proteção do ambiente, certamente, depende do que se entenda por ambiente e, consequentemente, do que se pretenda proteger.

Os Organismos Geneticamente Modificados [OGM] têm sido um dos pontos mais controvertidos quando se trata de proteção ao meio ambiente e de aplicação do princípio da precaução [PP]. A norma (EC) $n^{0}$ 178/2002 do Parlamento Europeu e do Conselho da Europa estabeleceu os princípios gerais e os requerimentos, ao instituir a autoridade de segurança alimentar europeia, permite que os Estadosmembros possam, com base no PP e, em circunstâncias específicas, adotar medidas provisórias de gerenciamento de riscos quando há possibilidade de efeitos deletérios ao meio ambiente, persistindo a incerteza científica em relação ao OGM.

Em função disso, diversos países europeus proibiram o cultivo e lançamento de OGMs no ambiente, certamente como o objetivo de assegurar um "nível elevado" de proteção ambiental. Todavia, a Corte Europeia de Justiça (julgamento no Caso C - 111/Giorgio Fidenato e outros ${ }^{2}$ ), em sentido contrário, não aceitou a proibição genérica e baseada em conceitos abstratos de risco. O Tribunal decidiu que, "quando não é evidente que os produtos geneticamente modificados constituam um risco grave para a saúde humana, a saúde animal ou o meio ambiente", nem a Comissão, nem os Estados-Membros podem

2 Em 1998, a Comissão Europeia autorizou a comercialização do milho geneticamente modificado MON 810. Na sua decisão, a Comissão se baseou em parecer do Comitê Científico, que afirmava não haver razão para acreditar que esse produto teria efeitos adversos sobre a saúde humana ou meio ambiente.Em 2013, o Governo italiano solicitou à Comissão que adotasse medidas de emergência para proibir o cultivo de milho MON 810 à luz de alguns novos estudos científicos realizados por dois institutos de pesquisa italianos. Com base em um parecer científico emitido pela Autoridade Europeia para a Segurança dos Alimentos (EFSA), a Comissão concluiu que não havia novas evidências científicas para apoiar as medidas de emergência solicitadas e invalidar suas conclusões anteriores sobre a segurança do milho MON 810. Apesar disso, em 2013, o governo italiano adotou um decreto ministerial que proibiu o cultivo do milho MON 810 na Itália. Em 2014, Giorgio Fidenato e outros cultivaram o milho MON 810 em violação do decreto ministerial,tendo sido processados criminalmente. No contexto de processos criminais contra essas pessoas, o Tribunal Distrital de Udine, Itália, consultou a Corte Europeia, em particular, se medidas de emergência, em relação aos alimentos, poderiam ser tomadas com base no princípio da precaução. 
adotar medidas de emergência como a proibição do cultivo de milho MON 810. Logo, a vedação de retrocesso não é um princípio soberano que se sobreponha às realidades de fato, devendo os riscos serem, minimamente, previsíveis.

\section{DIREITO AMBIENTAL E SISTEMA JURÍDICO}

O Direito é um sistema complexo que se estrutura sobre bases múltiplas, não se confundindo apenas com as normas positivadas. Contudo, no modelo jurídico brasileiro, cuja tradição se filia à família romano-germânica, a norma escrita é importantíssima, sendo o eixo central ao redor do qual os demais elementos da ordem jurídica gravitam; O Direito Ambiental, como parte da ordem jurídica, não se afasta do modelo.

O sistema jurídico, e o papel dos princípios nele, não é meramente formal. Os princípios se fundamentam em preceitos éticos, os quais devem ser incorporados às normas, buscando-se, na medida do possível, eliminar as suas contradições, sob pena de inoperância e desestabilização da ordem normativa. Os princípios jurídicos refletem uma tradição jurídica consolidada que é convocada para dar solução a questões que se encontrem em aberto. Na velha lição de Hans Kelsen (1979), a ordem jurídica não deve se contradizer, ainda que se reconheça que há um crescente "especialização" do Direito, com proposições que, muitas vezes, guardam colisão de sentido com outras. Assim, os princípios do Direito Ambiental integram os princípios gerais de direito e, portanto, são partes de uma ordem jurídica sistemática e que busca a estabilidade, como é inerente ao próprio Direito. A propósito, François Ewald (1993) relembra que os princípios gerais do direito objetivam primariamente a estabilidade e a continuidade da ordem jurídica, não se prestando, portanto, ao papel de desbravadores de novas sendas. 
Todavia, não seria excessivo afirmar que, na atual quadra do Direito Ambiental brasileiro, vive-se um momento de hipertrofia dos princípios, dada a sua evocação constante para solução de casos concretos corriqueiros e, portanto, perfeitamente subsumíveis às normas vigentes no ordenamento positivo, gerando um conjunto de princípios peculiares com pretensões a "direito revolucionário", apartado do sistema jurídico mais amplo, constituindo-se em um auto proclamado ápice paralelo, ou mesmo superior, à norma constitucional, ou dela se constituindo em um setor privilegiado, com preempção sobre os demais. A propósito, a relação entre o excesso de princípios e o sistema jurídico foi muito bem equacionada por ClausWilhelm Canaris (1996) ao afirmar que não é uma aberração que se entenda que a ideia de sistema jurídico encontra sua justificação no princípio da justiça e de seus desdobramentos no princípio da igualdade e na vocação para a generalização, o que encontra eco em outro "valor supremo" que é a segurança jurídica. Ela, segundo o autor, permite que o Direito seja previsível e determinável a priori. Isto implica na estabilidade e na continuidade da legislação e da jurisprudência e torna factível a aplicação prática do Direito. Do ponto de vista concreto, os objetivos de estabilidade e segurança - bem assim como os da justiça - são alcançáveis mais facilmente com um Direito ordenado, claro e estável e nunca por princípios esparsos, fazendo as vezes de guia para a aplicação aleatória de normas contraditórias, singulares e desconexas.

\section{A CONSTRUÇÃO DO MITO DO PROGRESSO}

A ideia de regresso é uma contraposição à ideia do progresso, enquanto nesta se faz um movimento adiante, naquela o movimento é em direção à retaguarda. Conforme observado por Dupas (2006) em termos sociais e filosóficos, o progresso parte do pressuposto de que a civilização (ou civilizações) se dirige em direção a um futuro "benévolo", no qual haverá mais felicidade, uma utopia. Cuida-se de 
uma ideia-força que pode ser vista como resultado da ação humana, planejada ou não, ou como um "processo inexorável" e, portanto, independente da ação humana. Esta forma de pensamento é antiga, muito embora tenha sido reforçada na modernidade. Dada a proeminência e força do mito do progresso, qualquer circunstância histórica que remeta ao desfazimento do que foi considerado como "progresso" passa a ser identificado como "regresso", volta ao passado.

Assim, a concepção subjacente ao princípio da vedação de regresso é a de que há um destino a ser cumprido e que a História se realizará inexoravelmente, sempre em sentido evolutivo em direção a um futuro melhor. Este entendimento (historicismo) do mundo tem duas vertentes principais: (1) a doutrina do povo escolhido ou eleito, mediante a qual Deus é identificado como autor do drama em que se constitui a História, pressupondo a existência de um povo escolhido como instrumento pelo qual a vontade divina se concretizará e que tal povo herdará a Terra. Assim, a vontade divina é o elemento impulsionador ou diretor da História, cujas leis podem ser identificadas por uma correta compreensão dos desígnios divinos; (2) a filosofia histórica que identifica em determinados grupos sociais, classes ou partidos, os portadores dos destinos da História. Este modelo tem em Hegel o seu fundador (POPPER, 2015).

$\mathrm{Na}$ segunda metade do século $\mathrm{XX}$, criou-se uma nova religião laica, cujo cânone é a vedação do retrocesso, A crença moderna, o ambientalismo e os ambientalistas podem ser caracterizados como,

Difusos, incoerentes, uma salada" estes são apenas alguns dos epítetos frequentemente lançados às pessoas que se autodenominam "verdes". Sobretudo, quando eles falam acerca do que a sociedade é e deveria ser. Estas crenças parecem provir de "todos os lados". São uma mélange de ideias associadas tradicionalmente ao centro, à direita e à esquerda políticos, misturadas com princípios retirados da ciência da ecologia. Os verdes podem negar incoerência, reivindicando uma distinção baseada no "biocentrismo" (...) Ou podem argumentar que, ao contrário de uma fraqueza, a diversidade de ideias é uma força política. (PEPPER, 2015, p. 25). 
Do ponto de vista político, a sociedade futura, o progresso e a nova era das luzes, ficam relegados a um futuro distante e cômodo, pois quaisquer sejam as dificuldades presentes, estas serão resolvidas em um amanhã que nunca chega. É inegável, portanto, o caráter utópico do historicismo em suas diversas manifestações. No que concerne ao ambiente e à sua proteção o historicismo se manifesta mediante uma crítica acerba do processo industrial e de suas repercussões sobre a biosfera indicando um futuro distópico, ou uma utopia negativa. Ao revés de um futuro brilhante e próspero, no qual a natureza e seus componentes sejam respeitados, imagina-se um mundo no qual as condições ambientais serão agravadas de tal forma que se tornará insuportável, hostil à vida em todas as suas formas e, sobretudo, hostil à vida humana.

Diferentemente do passado, a distopia ambiental está baseada em verdades científicas que, em tal condição, seriam inquestionáveis. Não se busca, todavia, negar as evidentes dificuldades sofridas pelo ambiente em função do crescimento populacional, aumento exponencial da atividade econômica, em especial a industrial. Conforme observado por DOUGLAS (1995), nos últimos séculos o ambiente foi modificado drasticamente, ninguém deve negar os efeitos que foram sofridos pelas florestas, pelas zonas úmidas, havendo consenso em relação a isto. A questão que deve ser enfrentada é a divergência em relação ao futuro. Com efeito, ainda que determinadas questões relativas ao futuro, mudanças climáticas globais, tendam a um consenso científico, o mesmo não se pode dizer das possíveis soluções para o problema (HULME, 2013).

A noção de um progresso constante foi amplamente fortificada com o otimismo que passou a imperar, sobretudo, na Europa Ocidental e nos Estados Unidos dado o espetacular crescimento econômico que tais regiões tiveram a partir de meados da década de 50 até o final da década de 60 do século XX (KERSHAW, 2018). No momento em que o forte impacto da primeira grande crise do petróleo 
atingiu a Europa e que a chamada geração dos Baby Boomers ${ }^{3}$ começou a envelhecer, as quedas nos índices de natalidade na Europa e a maior afluência de imigrantes, que não compartilhavam os valores europeus, ao Velho Continente, o otimismo se transformou em pessimismo, fazendo com que populações envelhecidas gritassem contra o "retrocesso". O pessimismo e a desesperança em relação ao porvir podem ser muito bem caracterizadas pelas obras de Jared Diamond (2005 e 2014) que olha para o passado, identificando civilizações que entraram em "colapso" e indicando que devemos aprender com sociedades "tradicionais" como forma de enfrentar problemas atuais cujas características são inteiramente distintas daquelas situações passadas por ele apontadas. Note-se que a própria noção de "colapso" tem sido fortemente criticada (McANANY; YOFFEE, 2012).

O princípio da vedação de retrocesso é mais um dos tantos princípios que proliferam no campo específico do Direito Ambiental, tal como este tem sido compreendido no Brasil, ostentando um claro "perfil fundamentalista". (ANTUNES, 2016) Mas, afinal do que se fala? Inicialmente há que se consignar que a ideia de vedação ao retrocesso, em quaisquer de seus aspectos, traz consigo a noção de que a humanidade e suas obras estão finalisticamente destinadas à evolução constante e que, em tal condição, não há retrocesso a situações pretéritas. O "retrocesso" embora não desejável é uma presença constante na História da Humanidade e suas origens estão vincadas em situações de fato complexas e para as quais o Direito não é capaz de dar respostas ou impedir que se concretizem.

\subsection{A Questão do Desenvolvimento Sustentável}

Países como o Brasil e tantos outros são considerados em vias de desenvolvimento pela Organização das Nações Unidas e, portanto,

\footnotetext{
3 Pessoa nascida especialmente na Europa e Estados Unidos entre 1946 e 1964.
} 
buscando o desenvolvimento. Há, portanto, uma aparente contradição, entre a necessidade de desenvolvimento do País e a vedação de retrocesso (ONU, 2014). Conforme será visto mais adiante neste artigo, a invocação judicial do princípio da vedação de retrocesso, inexoravelmente, tem por objetivo paralisar atividades econômicas que, segundo os críticos, geram externalidades negativas. Não é ocioso lembrar que, no texto da mesma Constituição (artigo $3^{\circ}$, incisos II e III), estão estabelecidos outros "objetivos fundamentais" (garantia do desenvolvimento nacional e erradicação da pobreza e da marginalização, assim como a redução das desigualdades sociais e regionais) da República que, necessariamente, geram friç̧ão com a proteção do meio ambiente. Isto ocorre por que a interpretação das normas constitucionais é essencialmente política e, como tal, deve responder às realidades concretas que se apresentam ante os seus aplicadores e intérpretes. Identificar, na Constituição, o conceito de desenvolvimento sustentável pouco ajuda na solução do problema, dado que tal conceito é demasiadamente aberto e tem sofrido críticas fortíssimas por diversas correntes políticas, críticas, não raras vezes, contraditórias. (DUPAS, 2006, p. 236).

O desenvolvimento sustentável, conforme a definição que lhe foi dada pela Comissão Brundtland (COMISSÃO MUNDIAL SOBRE MEIO AMBIENTE E DESENVOLVIMENTO, 1988) é o capaz de satisfazer as necessidades do presente sem comprometer a capacidade das gerações futuras em satisfazer às suas próprias necessidades. Embora ele seja amplamente adotado e reconhecido, não se pode deixar de observar que é um conceito amplíssimo e, francamente, pouco operacional. Em primeiro lugar cumpre indagar quais são as necessidades do presente? No presente, existem necessidades extremamente diversas e, até mesmo, incompatíveis. Quem define o que deve ser entendido por necessidades? Quais necessidades são prioritárias? Quando se fala em gerações futuras, qual é o horizonte temporal que temos em mente? Se identificar as necessidades presentes não é uma questão simples, como identificar as necessidades de um futuro cujo marco temporal é indefinido? Podemos impor os 
nossos conceitos de necessidade, ainda que fluídos, às gerações que ainda não nasceram?

Há quem sustente a substituição do conceito de desenvolvimento sustentável pelo andino "Bem Viver" (SOLÓN, 2019), ou mesmo pelo de “decrescimento" (LÉNA; NASCIMENTO, 2012). O que a Constituição faz, em termos de proteção ambiental é estabelecer os limites legais dentro dos quais as disputas políticas sobre a utilização dos recursos naturais ocorrerão. Em acréscimo é importante ressaltar que conceitos sociais tais como, democracia, justiça, liberdade, poder, responsabilidade e tantos outros são igualmente contestados e contestáveis; todavia, possuem em comum o fato de serem centrais na vida política das sociedades humanas (LENZI, 2006, pg. 92).

\section{VEDAÇÃO DE RETROCESSO, DIREITO INTERNACIONAL DO MEIO AMBIENTE E DIREITOS HUMANOS E SOCIAIS}

No âmbito do Direito Internacional não se pode falar em existência do princípio da vedação do retrocesso, tal como tem sido compreendido por parte relevante da comunidade jurídica brasileira. Com efeito, ao analisar o Direito Internacional do Meio Ambiente LEITE et al (2015, p. 114) afirmam que a Convenção de Diversidade Biológica [CDB] e a Convenção de Ramsar [RAMSAR] expressam de forma mais “destacada” a questão relativa à proibição de regresso ambiental. Todavia, leitura mais atenta dos textos convencionais, ambos incorporados ao direito brasileiro, indica que os Estados podem “retroceder” quanto à proteção bens por eles tutelados. Inicialmente, há que se observar que ambos os acordos internacionais sobre meio ambiente admitem denúncia (CDB artigo 38 e RAMSAR artigo 11), ou seja, a retirada das Partes que, em tese, é o "retrocesso" mais radical. Não se esqueça que, no caso específico do Acordo de Paris (Decreto $\mathrm{n}^{\circ}$ 9.073, de 5 de junho de 2017) sobre mudanças climáticas, os Estados 
Unidos dele se retiraram, invocando o direito de denúncia (artigo 28) e, ninguém tem dúvida, do significado "regressivo" de tal gesto. No caso específico da Convenção de RAMSAR, a posição "regressista" também é muito clara, pois ela expressamente admite em seu artigo 2 (5) que qualquer uma das Partes Contratantes poderá aumentar o número de zonas úmidas situadas em seu território como objeto especial de proteção ou, "por motivo de interesse nacional urgente, anular ou restringir os limites das zonas úmidas já por ela incluídas na Lista", ou seja, poderá "retroagir" no nível de proteção conferida às aludidas zonas úmidas.

Por fim, não se pode esquecer que os acordos ambientais multilaterias admitem a possibilidade de denúncia, o que, por si só, é uma "regressão" no nível de proteção outorgada pelo acordo, haja vista que o Estado se desobriga em relação ao estipulado no documento internacional.

\subsection{Acordos Multilaterais sobre Direitos Humanos e Sociais}

No que tange aos Direitos Humanos propriamente ditos, o Pacto Internacional sobre Direitos Econômicos, Sociais e Culturais [PIDESC], incorporado ao direito brasileiro (Decreto $\mathrm{n}^{\circ}$ 591, de $06 \mathrm{de}$ julho de 1992) abriga a possibilidade legal de limitação dos direitos nele consignados, desde que observados critérios fixados pelo próprio PIDESC. Merece ser ressaltado que tal documento internacional, claramente, possui dispositivos relativos ao meio ambiente e sua proteção, estabelecendo o seu artigo $1^{\circ}$ (2) que, "todos os povos podem dispor livremente de suas riquezas e de seus recursos naturais", não se admitindo "[e]m caso algum" que um povo possa ser privado de seus meios de subsistência. Os direitos definidos no PIDESC deverão ser assegurados "progressivamente" artigo $2^{\circ}$ (1), ou seja, a sua implantação não se faz de forma imediata, mas, conforme os "recursos disponíveis". 
No que diz respeito à chamada proibição de retrocesso ou regressão, é de se registar que o artigo $4^{\circ}$ admite que eles possam ser submetidos "às limitações estabelecidas em lei”, a qual deverá ser "compatível com a natureza desses direitos e exclusivamente com o objetivo de favorecer o bem-estar geral em uma sociedade democrática”. Por fim, e neste caso, diretamente relacionado com a utilização dos recursos naturais, determina o artigo 25 que o PIDESC não deverá ser interpretado como uma restrição a nenhum de "desfrutar e utilizar plena e livremente suas riquezas e seus recursos naturais". Pelo que se pode perceber, o PIDESC expressamente reconhece aos Estados Parte o direito de definir os contornos concretos dos direitos nele estabelecidos, inclusive com as limitações que a lei nacional venha a estabelecer.

Também merece menção o fato de que a Corte Interamericana de Direitos Humanos [CIDH], no conhecido caso Saramaka (CORTE IDH, 2007), entendeu que há possibilidade legal de restrição de direitos humanos, desde que observadas as regras impostas pela Convenção Interamericana de Direitos Humanos [Convenção]. A CIDH entende que o direito estabelecido no artigo 21 da Convenção não é absoluto e, em tal condição, não permite uma interpretação tão estrita. Mesmo reconhecendo a importante interconexão entre o direito dos membros dos povos indígenas e tribais ao uso e gozo de suas terras e o direito aos recursos necessários para sua sobrevivência, estes direitos de propriedade, como muitos outros direitos reconhecidos na Convenção, estão sujeitos a certos limites e restrições. Como se sabe, o artigo 21 da Convenção estabelece que a lei pode subordinar o uso e gozo dos bens ao interesse social, inclusive os bens de propriedade de povos indígenas e tribais. Por diversas vezes a CIDH tem afirmado que, conforme o artigo 21 da Convenção, o Estado pode restringir o uso e gozo do direito à propriedade sempre que as restrições: a) tenham sido previamente estabelecidas por lei; b) sejam necessárias; c) sejam proporcionais e d) que busquem alcançar um objetivo legítimo em uma sociedade democrática. 
Assim, parece ser evidente que a CIDH admite que, em certas circunstâncias, os direitos humanos podem ser restringidos, demonstrando que, mesmo em área tão sensível, não cabe uma alegação genérica de proibição de retrocesso sem que se leve em consideração o caso concreto.

\section{ALTERAÇÃO E SUPRESSÃO DE ETEPS NO DIREITO BRASILEIRO}

A possibilidade legal alteração de ETEPs, inclusive no que se refere à sua supressão é tema antigo. Entretanto, como se verá neste tópico, a supressão de ETEP é comum no Direito Brasileiro e tem sido referendada pelo Supremo Tribunal Federal em seguidas oportunidades. A supressão de ETEPs é ato que, em tese, implica em flagrante violação do assim chamado princípio da vedação do retrocesso ambiental e, em tal condição, incompatível com a “Constituição Ecológica” ora vigente no Brasil. Contudo, como se demonstrará neste tópico, é medida expressamente prevista na Constituição da República, desde que observados certos pressupostos.

Se examinarmos o desenvolvimento da legislação brasileira relativa aos ETEP, se perceberá que ao aumento físico de tais áreas correspondeu um progressivo abrandamento das restrições por eles estabelecidas para o desempenho de atividades econômicas. Com efeito, o Decreto $\mathrm{n}^{0}$ 4.421, de 28 de dezembro de 1921 que criou o Serviço Florestal do Brasil reconheceu os seguintes ETEP: as (1) Florestas protetoras do domínio da União, nas quais somente seria permitido o aproveitamento econômico "em casos de grande vantagem para a riqueza pública”, as (2) reservas florestais, constituídas por terras públicas federais e por outras cedidas gratuitamente pelos governos estaduais. As terras particulares poderiam ser incluídas nas reservas mediante acordo com "os respectivos proprietários" para permuta ou compra, mediante aprovação do Congresso Nacional e os (3) parques nacionais criados 
em "locais caracterizados por acidentes topográficos notáveis, grandiosos e belos e encerrando florestas virgens típicas, que serão perpetuamente conservadas”.

É importante observar que o Código Florestal de 1934 (aprovado pelo Decreto $\mathrm{n}^{\circ} 23.793$, de 23 de janeiro), em seu artigo $9^{\circ}$ não foi tão explícito quanto ao caráter perpétuo dos parques que se “constituem monumentos públicos naturais, que perpetuam em sua composição florística primitiva, trechos do país, que, por circunstancias peculiares, o merecem”. Já as florestas protetoras e as remanescentes eram consideradas de "conservação perene" e inalienáveis, salvo se os adquirentes e os seus herdeiros se obrigassem com a manutenção do regime legal.

O Código Florestal de 1965 (Lei n ${ }^{\circ}$ 4.771), em seu artigo $5^{\circ}$ não fez qualquer menção à perpetuidade dos parques. Ao dispor sobre as áreas de preservação permanente [APP], o $\S 1^{\circ}$ do artigo $3^{\circ}$ admitiu a sua supressão "total ou parcial”, mediante autorização do Executivo, "quando for necessária à execução de obras, planos, atividades ou projetos de utilidade pública ou interesse social.”

A Lei $n^{0}$ 6.902, de 27 de abril de 1981 ao disciplinar as Estações Ecológicas [EE], em seu artigo $7^{\circ}$ estabeleceu que as EE não poderiam "ser reduzidas nem utilizadas para fins diversos daqueles para os quais foram criadas”. Entretanto, cerca de dois meses após a edição da Lei no 6.902/1981, o Decreto no 86.071, de 04 de junho de 1981 extinguiu o Parque Nacional de Sete Quedas que havia sido criado pelo Decreto n ${ }^{\circ}$ 50.665, de 30 de maio de 1961.

A Lei do Sistema Nacional de Unidades de Conservação [SNUC] revogou o artigo $5^{\mathrm{o}}$ da Lei $\mathrm{n}^{0} 4,771 / 1965$, dando nova regulamentação aos Parques Nacionais, nada dispondo sobre a sua perpetuidade, assim como também não o fez em relação às Reservas Ecológicas. Todavia, no artigo 22, $\S 7^{0}$ dispôs sobre a desafetação ou redução das Unidades de Conservação. Afetação, em Direito Administrativo, como se sabe, é a destinação de fato ou jurídica de um bem público à uma utilidade pública (MOREIRA NETO, 2005), sendo 
a desafetação, a redução ou extinção, fática ou legal, da utilização de interesse público de um determinado bem. A norma, claramente, não afronta ao disposto no inciso III do $\S 1^{\circ}$ do artigo 225 da Lei Fundamental da República que, muito embora não se utilize do termo técnico desafetação, fala em "supressão", ou seja a dação de um destino diverso à UC.

$\mathrm{Na}$ legislação ordinária são inúmeros os exemplos de "retrocesso" na proteção ambiental em benefício de outros bens e valores. Devendo ser observado que todos os "retrocessos" foram julgados constitucionais pelas Cortes de Justiça brasileiras. A Mata Atlântica, como se sabe, é patrimônio nacional ( $\mathrm{CF}$ artigo 225, $\S 4^{\circ}$ ) e merecedora de uma lei federal especificamente destinada à sua proteção (Lei $n^{0}$ 11.428/2006), entretanto, a própria Lei da Mata Atlântica reconhece a existência de valores superiores à própria preservação de sua vegetação primária, ao autorizar o seu corte, "em caráter excepcional", quando "necessários à realização de obras, projetos ou atividades de utilidade pública, pesquisas científicas e práticas preservacionistas.” (Artigo 20). Não há dúvida que se está diante de um "retrocesso".

O mesmo fenômeno ocorre em relação ao Novo Código Florestal [NCF] que, no particular incorporou disposição já prevista no revogado Código Florestal, no que se refere à possibilidade de supressão de áreas de APPs em função da existência de (1) utilidade pública ou (2) interesse social. Veja-se que, em tais hipóteses, são contemplados interesses que, no caso concreto, implicam em "retrocesso" em relação ao nível de proteção outorgado pelo regime jurídico aplicável às APPs.

\subsection{Vedação do Retrocesso no Supremo Tribunal Federal}

O Supremo Tribunal Federal [STF], assim como o Superior Tribunal de Justiça [STJ], apreciou diversas questões relativas ao chamado princípio da vedação de retrocesso em matéria de proteção 
ambiental e, em especial, sobre o NCF. Com efeito, o NCF foi amplamente questionado perante a Corte (BRASIL, 2019), por meio de diferentes ações diretas de controle de constitucionalidade. Conforme decidido pela Corte Constitucional, as políticas públicas ambientais necessitam ser compatíveis com "outros valores democraticamente eleitos pelos legisladores como o mercado de trabalho, o desenvolvimento social, o atendimento às necessidades básicas de consumo dos cidadãos etc.”. O Ministro relator, Luiz Fux, prossegue afirmando a inadequação de se desqualificar normas contidas no NCF "sob o genérico e subjetivo rótulo de retrocesso ambiental, ignorando as diversas nuances que permeiam o processo decisório do legislador, democraticamente investido da função de apaziguar interesses conflitantes por meio de regras gerais e objetivas.” O Ministro relembrou que a mesma Constituição que protege o meio ambiente, igualmente, alberga outros valores tais como: a (1) livre iniciativa (artigos $1^{\mathrm{o}}$, IV, e 170), o (2) desenvolvimento nacional (art. $\left.3^{\circ}, \mathrm{II}\right)$, a (3) erradicação da pobreza e da marginalização, a (4) redução das desigualdades sociais e regionais (art. $3^{\circ}$, III; art. 170, VII), a (5) proteção da propriedade (art. $5^{\circ}$, caput e XXII; art. 170, II), a (6) busca do pleno emprego (art. 170, VIII; art. $6^{\circ}$ ) e a (7) defesa do consumidor (art. $5^{\circ}$, XXXII; art. 170, V) etc.

O STF, na ADC 42, decidiu que a proteção do meio ambiente "não equivale a uma visão estática dos bens naturais, que pugna pela proibição de toda e qualquer mudança ou interferência em processos ecológicos ou correlatos. A história humana e natural é feita de mudanças e adaptações, não de condições estáticas ou de equilíbrio”. Enfrentando a questão específica do princípio da vedação do retrocesso, o STF decidiu que: "O Princípio da vedação do retrocesso não se sobrepõe ao princípio democrático no afã de transferir ao Judiciário funções inerentes aos Poderes Legislativo e Executivo, nem justifica afastar arranjos legais mais eficientes para o desenvolvimento sustentável do país como um todo”. A ADC 42. inclusive, afastou a incidência de mais um "princípio inovador", no caso o in dubio pro 
natura, haja vista que nem sempre a norma aparentemente mais favorável ao meio ambiente deve prevalecer, pois diferentes interesses precisam ser avaliados para fundamentar a decisão, "reconhecendo-se a possibilidade de o regulador distribuir os recursos escassos com vistas à satisfação de outros interesses legítimos, mesmo que não promova os interesses ambientais no máximo patamar possível". (BRASIL, 2018)

É preciso deixar consignado que a decisão acima exposta, segue a linha de precedentes já consolidados perante o STF, como é o caso do RE $\mathrm{n}^{0}$ 586.224/SP (Rel. Ministro Luiz Fux) quando foi examinado conflito entre lei municipal (município de Paulínia, Lei ${ }^{\circ}$ 1.952/1995) e lei estadual (São Paulo, Lei no 11.241/2002) relativas à queima de palha da cana-de-açúcar. A lei municipal bania a atividade, enquanto que a lei estadual estabelecia um processo de superação progressiva e escalonada da queima. No caso em tela, o Tribunal decidiu que, apesar da lei municipal aparentemente conferir maior proteção ao meio ambiente, esta deveria ceder ante a norma que estipulou um cronograma para adaptação do cultivo da cana-deaçúcar a métodos sem a utilização do fogo.

\subsubsection{SUPRESSÃO DE UNIDADE DE CONSERVAÇÃO E LEI EM SENTIDO ESTRITO}

O STF tem entendimento no sentido de que somente lei formal pode dispor sobre alteração e/ou supressão de UCs, a hipótese, no caso concreto, dizia respeito à conversão da Medida Provisória [MP] $\mathrm{n}^{\circ} 472 / 2009$, na qual foram incluídos, por emenda parlamentar, os artigos 113 a 126, versando sobre alteração de limites de unidades de conservação, na redação final da Lei ${ }^{0}$ 12.249/2010, resultante da conversão da MP no 472/2009. A nova lei foi julgada inconstitucional por "afronta ao princípio democrático, ao postulado da separação entre os Poderes e à garantia do devido processo legislativo, à ausência de pertinência temática entre a matéria veiculada na emenda 
parlamentar e o objeto da medida provisória submetida à conversão em lei" (BRASIL, 2010).

Em outra oportunidade, o STF enfrentou matéria assemelhada, muito embora a Ministra Relatora Cármen Lúcia, tenha invocado a vedação de retrocesso, ainda que tangencialmente. (BRASIL, 2019) A Lei no 12.678/2012 é o resultado da conversão da MP $n^{\circ} 558 / 2012$ que alterou UCs, todavia, o STF entendeu que "as medidas provisórias não podem veicular norma que altere espaços territoriais especialmente protegidos, sob pena de ofensa ao artigo 225, inciso III, da Constituição da República." O argumento foi suficiente para fulminar a constitucionalidade da norma impugnada, não havendo necessidade de quaisquer recursos a princípios abstratos, haja vista que as alterações propostas na lei "atingiram o núcleo essencial do direito fundamental ao meio ambiente ecologicamente equilibrado previsto no artigo 225 da Constituição da República”. É importante realçar que o Poder Executivo tem entendimento semelhante, vetando alterações em Medidas Provisórias que reduzem UCs.

\subsubsection{SUPRESSÃO DE OUTROS ESPAÇOS TERRITORIAIS ESPECIALMENTE PROTEGIDOS}

Várias discussões relevantes sobre o tema foram travadas no

STF, a começar pelo julgamento da Ação Direta de Inconstitucionalidade, com pedido de medida cautelar, contra a MP 2.166-67; 2001, especialmente em relação a parte que alterou os artigos $4^{\circ}$ e seus parágrafos da Lei $n^{0} 4 \cdot 771 / 1965$. Em síntese, a MP autorizava o Conselho Nacional do Meio Ambiente a dispor, mediante Resolução, sobre a supressão de APPs. No entendimento do Procurador-Geral da República, a norma violava o inciso III do $\S 1^{\circ}$ do artigo 225 da Constituição Federal, pois da norma constitucional, se depreendia, que somente a lei em sentido formal e específica, 
entendida esta como ato normativo emanado do Poder Legislativo...poderá autorizar a alteração e/ou supressão de ETEPs. Entretanto, o STF julgou improcedente a ADI, entendendo que a alteração do artigo $4^{\circ}$ do Código Florestal, como proposto pela MP, se constituiu em “avanço expressivo”, sob o argumentou que,

\begin{abstract}
A Medida Provisória no 2.166-67, de 24/08/2001, na parte em que introduziu significativas alterações no artigo $4^{\circ}$ do Código Florestal, longe de comprometer os valores constitucionais consagrados no artigo 225 da Lei Fundamental, estabeleceu, ao contrário, mecanismos que permitem um real controle, pelo Estado, das atividades desenvolvidas no âmbito das áreas de preservação permanente, em ordem a impedir ações predatórias e lesivas ao patrimônio ambiental, cuja situação de maior vulnerabilidade reclama proteção mais intensa, agora propiciada, de modo adequado e compatível com o texto constitucional, pelo diploma normativo em questão. Somente a alteração e a supressão do regime jurídico pertinente aos espaços territoriais especialmente protegidos qualificam-se, por efeito da cláusula inscrita no artigo 225, $\S 1^{\circ}$, III, da Constituição, como matérias sujeitas ao princípio da reserva legal. - É lícito ao Poder Público - qualquer que seja a dimensão institucional em que se posicione na estrutura federativa (União, Estadosmembros, Distrito Federal e Municípios) - autorizar, licenciar ou permitir a execução de obras e/ou a realização de serviços no âmbito dos espaços territoriais especialmente protegidos, desde que, além de observadas as restrições, limitações e exigências abstratamente estabelecidas em lei, não resulte comprometida a integridade dos atributos que justificaram, quanto a tais territórios, a instituição de regime jurídico de proteção especial (CF, art. 225, $\S 1^{\circ}$, III). (BRASIL, 2001)
\end{abstract}

Tal entendimento foi consolidado com a decisão proferida na ADC 42. Especificamente em relação aos ETEPs, as decisões tomadas pelo STF foram diversas, sendo marcadas pelo pragmatismo e respeitando o complexo processo de construção do NCF. Inicialmente foi decidido que havia de ser dada interpretação conforme aos incisos VIII e IX do artigo $3^{\circ}$ da Lei $\mathrm{n}^{\circ} 12.651 / 2012$, condicionando-se a intervenção excepcional em APP, por interesse social ou utilidade pública, à inexistência de alternativa técnica e/ou locacional para a atividade proposta, e declarando-se a inconstitucionalidade das expressões gestão de resíduos e instalações necessárias à realização 
de competições esportivas estaduais, nacionais ou internacionais, contidas no artigo $3^{\circ}$, VIII, b. Também foi dada interpretação conforme ao artigo $4^{\circ}$, inciso IV, da Lei $\mathrm{n}^{\circ} 12.651 / 2012$, com vistas a reconhecer que os entornos das nascentes e dos olhos d'água intermitentes configuram APP.

Outro ponto fortemente criticado como "retrocesso" do NCF foi a alteração do conceito de leito regular de rio ou curso d água. Conforme decidido pelo STF, "a legislação em vigor tão somente modificou o marco para a medição da área de preservação ambiental (sic) ao longo de rios e cursos d água, passando a ser o leito regular respectivo, e não mais o seu nível mais alto." O Tribunal entendeu que o legislador é dotado de discricionariedade para modificar a metragem de áreas de preservação ambiental, na medida em que o artigo 225, § $1^{\circ}$, III, da Constituição, expressamente permite que a lei altere ou suprima espaços territoriais e seus componentes a serem especialmente protegidos, não havendo inconstitucionalidade a ser declarada.

Um outro "retrocesso" amplamente criticado foi o tratamento específico da matéria relativa às pequenas propriedades ou posses familiares rurais (imóveis com até 4 módulos fiscais). O STF entendeu como legítimo o critério "para a incidência das normas especiais sobre Áreas de Preservação Permanente e de Reserva Legal previstas nos artigos 52 e seguintes do novo Código Florestal", valendo o mesmo para a inscrição no cadastro ambiental rural (CAR) e para o controle e a fiscalização efetivada pelos órgãos ambientais.

Quanto às APPs situadas no entorno de reservatórios artificiais que não decorram de barramento de cursos d'água naturais e de reservatórios naturais ou artificiais com superfície de até um hectare, entendeu o STF que não houve supressão de tais APPs pelo NCF, tendo a lei delegado ao órgão que promover a licença ambiental do empreendimento a tarefa de definir a extensão da APP, conforme caso concreto. Como realçado pela Corte, a escolha legal evita os inconvenientes da solução one size fits all, assegurando a adequação 
da norma tutelar ao caso concreto, acrescentando que a pretensão de "constitucionalização da metragem" da APP contida na lei revogada ofendia o princípio democrático e a faculdade conferida ao legislador pelo artigo 225, $\S 1^{\circ}$, III, da Constituição para suprimir ou alterar espaços territoriais especialmente protegidos.

\section{CONCLUSÃo}

A ideia de progresso constante e de constante e de contínuas melhorais, como se o mundo e a humanidade caminhassem inexoravelmente em direção à uma era de ouro (historicismo) é a base de sustentação do chamado princípio da vedação do retrocesso. Análise mais pormenorizada da matéria demonstra que os próprios adeptos da existência da vedação de retrocesso, como princípio jurídico, são relutantes em afirmá-lo expressamente.

Por outro lado, a legislação posta e a própria Constituição Federal, se analisadas com isenção, certamente não albergam o princípio da vedação de retrocesso. Ao contrário, sob determinadas circunstâncias, admitem a redução da proteção de áreas verdes em favor de outros interesses igualmente protegidos pela Constituição Federal.

O Supremo Tribunal Federal, por sua vez, descartou a existência da vedação de retrocesso em matéria ambiental, sobretudo em relação ao $\mathrm{NCF}$ e ao SNUc, ainda que, acertadamente, tenha reconhecido de forma estrita os limites impostos pela Constituição Federal no que tange à modificação dos ETEPs.

De acordo com a argumentação acima desenvolvida, parece claro que o princípio da vedação de retrocesso ambiental é mais uma construção cerebrina de parte da doutrina e da $2^{\mathrm{a}} \mathrm{T}$ - STJ que não encontra eco relevante na doutrina e jurisprudência estrangeira, tampouco na Corte Constitucional Brasileira, ainda que haja muita persistência no desiderato de construir um "princípio novo" para o Direito Ambiental. A fragilidade teórica é inquestionável, até mesmo 
Princípio Da Vedação De Retrocesso Ambiental: Uma Visão Crítica

porque os seus principais teóricos, reconhecem que o princípio da vedação de retrocesso não encontra amparo na Constituição, nem na legislação infraconstitucional, como restou amplamente demonstrado no artigo.

Data de Submissão: 15/04/2020

Data de Aprovação: 22/04/2020

Processo de Avaliação: desk review

Editor Geral: Jailton Macena de Araújo

Editor de Área: Fernando Joaquim Ferreira Maia

Assistente Editorial: Maria Aurora Medeiros Lucena Costa

\section{REFERÊNCIAS}

ANTUNES, Paulo de Bessa. Direito Ambiental. 18 ${ }^{\text {a }}$ Edição. São Paulo: Atlas. 2016.

ARAGÃO, Alexandra. O direito constitucional do ambiente na União Europeia. In: CANOTILHO, José Joaquim Gomes e Leite, José Rubens Morato. Direito Constitucional Ambiental Brasileiro. $3^{\text {a }}$ ed. São Paulo: Saraiva, 2010.

BRASIL. Congresso Nacional. Senado Federal. Comissão de Meio Ambiente, Defesa do Consumidor e Fiscalização e Controle (CMA). Colóquio Internacional sobre o Princípio da Proibição de Retrocesso Ambiental. Brasília, DF. 2012.

CANOTILHO, José Joaquim Gomes. Estudos sobre Direitos Fundamentais. $2^{\mathrm{a}}$ ed. Coimbra: Almedina. 2008.

COMISSÃO MUNDIAL SOBRE MEIO AMBIENTE E DESENVOLVIMENTO. Nosso Futuro Comum. Rio de Janeiro: Fundação Getúlio Vargas. 1988.

CORNWALL, Andrea e EADE, Deborah. Deconstructing Development Discourse. Buzzwords and Fuzzwords, Oxford: Practical Action Printing and Oxfan, 2010. Disponível em : https://oxfamilibrary.openrepository.com/bitstream/handle/10546/ 118173/bk-deconstructing-development-buzzwords-010910en.pdf?sequence $=1$ \&isAllowed $=y$ Acesso em 11 mai. 2020. 
DERBLI, Felipe. O Princípio da Proibição de Retrocesso

Social na Constituição de 1988. Rio de Janeiro: Renovar, 2007.

DIAMOND, Jared. Colapso - como as sociedades escolheram o fracasso ou o sucesso (tradução de Alexandre Raposo). Rio de Janeiro: Record, 2005.

DIAMOND, Jared. O Mundo até ontem - o que podemos aprender com as sociedades tradicionais. (tradução de Maria Lúcia de Oliveira). Rio de Janeiro: Record, 2014.

DOUGLAS, Mary. Risk and Blame: essays in cultural theory. London and New York: Routledge. 1995.

DUMONT, René. Un monde intolérable: le libéralisme en question. Paris, Éditions du Seuil, Coll. « L'histoire immédiate », 1988.

DUPAS, Gilberto. $O$ Mito do Progresso. $2^{\text {a }}$ ed. Campinas: Unesp, 2006.

EWALD, François. Foucault: a norma e o direito (tradução: António Fernando Cascais). Lisboa: Vega. 1993.

EWALD, François; GOLLIER, Christian e SADELER, Nicolas de. Le Principe de Précaution, $2^{\mathrm{e}}$ Édition. Paris: PUF. 2008.

GARCIA, Maria da Glória F.P.D. O Lugar do Direito na Protecção do Ambiente. Coimbra: Almedina, 2015.

HEGEL, Georg Wilhelm Friedrich. Princípios da Filosofia do Direito. (Tradução de Orlando Vitorino). São Paulo: Martins Fontes, 1997.

HULME, Mike. Why we Disagree about Climate Change Understanding Controversy, Inaction and Opportunity. Cambridge: Cambrridge University Press. 2013.

JACCOUD, Cristiane; GIL, Luciana e MORAIS, Roberta Jardim (organizadoras). Súmulas do STJ em Matéria Ambiental Comentadas - um olhar contemporâneo do direito ambiental no judiciário. Londrina: Thoth, 2019.

KELSEN, Hans. Teoria Pura do Direito, (Tradução João Baptista Machado), Coimbra: Armênio Amado Editor, Sucessor, 1979.

KELSEN. Hans. A Ilusão da Justiça (tradução de Sérgio Tellaroli). São Paulo: Martins Fontes. 1995.

KERSHAW, Ian. Continente Dividido - A Europa 1950-2017

(tradução de Miguel Freitas da Costa). Alfregide: Dom Quixote. 2018. 
Princípio Da Vedação De Retrocesso Ambiental: Uma Visão Crítica

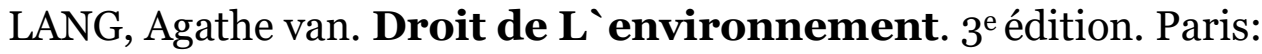
Presses Universitaires de France. 2011.

LEITE, José Rubens Morato (Coordenador). Manual de Direito Ambiental. São Paulo: Saraiva, 2015.

LÉNA, Philippe e NASCIMENTO, Elimar Pinheiro (organizadores). Enfrentando os Limites do Crescimento - sustentabilidade, decrescimento e prosperidade. Rio de Janeiro: Garamond, 2012.

LENZI, Cristiano Luis. Sociologia Ambiental - risco e sustentabilidade na modernidade. Bauru: EDUSC, 2006.

McANANY, Patricia A.; YOFFEE, Norman (edited by). Questioning Collapse - Human Resilience, Ecological Vulnerability, and the Aftermath of Empire. Cambridge: Cambridge University Press. 2012.

MELLO, Paula Suassuna Amaral. Direito ao Meio Ambiente e Proibição do Retrocesso. São Paulo: Atlas, 2014.

MORE, Thomas. Utopia. (Tradução de Anah de Melo Franco). Brasilia: Universidade de Brasília, 2004.

MOREIRA NETO, Diogo de Figueiredo. Curso de Direito Administrativo - Parte Introdutória, Parte Geral, Parte Especial. $14^{\mathrm{a}}$ ed. Rio de Janeiro: Forense, 2005.

PEPPER, David. Ambientalismo Moderno (tradução de Carla Lopes Silva Correa). Lisboa: Instituto Piaget. S/d.

POPPER, Karl R. Em busca de um mundo melhor (Tradução de Milton Camargo Mota). São Paulo: Martins, 2008.

POPPER, Karl. A Sociedade Aberta e seus Inimigos - Primeiro Volume: O Sortilégio de Platão (tradução de Miguel Freitas da Costa). Lisboa: Edições 70. 2015.

PRIEUR, Michel. Princípio da Proibição de Retrocesso Ambiental, in SENADO FEDERAL, O Princípio da Proibição de Retrocesso Ambiental, Brasília, 2012.

ROMI, Raphäel. Droit de Lènvironnement. Paris:

Montchrestien. $7^{\mathrm{e}}$ édition. 2010

SARLET, Ingo Wofgang e FENSTERSEIFER. Direito

Constitucional Ambiental (Constituição, Direitos Fundamantais e Proteção do Ambiente). $3^{\text {a }}$ ed. Sâo Paulo: RT, 2013.

SARLET, Ingo Wofgang; MACHADO, Paulo Affonso Leme e FENSTERSEIFER, Tiago. Constituição e Legislação Ambiental comentadas. São Paulo: Saraiva, 2015. 
SARLET, Ingo Wolfgang e FENSTERSEIFER, Tiago. Princípios do Direito Ambiental, São Paulo: Saraiva, 2014.

SCOONES, Ian. Sustainability, in, CORNWALL, Andrea e EADE, Deborah (Edited by). Deconstructing Development Discourse - Buzzwords and Fuzzwords, Oxford: Practical Action Printing and Oxfan, 2010.

SIRVINSKAS, Luís Paulo. Manual de Direito Ambiental.12 ${ }^{\text {a }}$ Edição. São Paulo: Saraiva, 2014.

SOLÓN, Pablo (organizador). Alternativas Sistêmicas Bem Viver, decrescimento, comuns, ecofeminismo, direitos da Mãe Terra e desglobalização. (tradução de João Peres). São Paulo: Elefante, 2019.

SUNSTEIN, Cass R. Laws of Fear - Beyond the Precautionary Principle. Chicago: Chicago University Press, 2005. 
Environmantal Setback Prohibition Principle: A Critical View

\author{
Paulo De Bessa Antunes
}

\begin{abstract}
The article aims to discuss the so-called environmental setback prohibition principle is a mechanical adaptation of historicism to environmental law and, in fact, does not find support in the Constitution, nor in the main decisions of the Supreme Federal Court. It is a construction that, however, has spread among the authors and some decisions of the Superior Court of Justice. The article demonstrates that more or less environmental protection, even with legislative changes, depends, essentially, on the economic situation.
\end{abstract}

Keywords: Environmetnal setback. Historicism. Environmetnal law. Environmetnal protection. 